\title{
Research Status and Application of AirSource Heat Pump Technology
}

\author{
Hongtao Meng,Jihui Tang,Haifeng Huang \\ School of Electrical Engineering, Nanjing Institute of Mechanical and Electrical Engineering, Jiangsu, China
}

\begin{abstract}
With the improvement of people's living standards, water heaters almost into the various households. In the energy-saving emission reduction has become the trend of the times today, saving energy and reducing carbon emissions is the most fashionable way of life. Air source heat pump water heaters are increasingly being used in people's lives. It is well known that it has many advantages, safety, energy saving, comfort, environmental protection, but there are some factors that affect its development and promotion. This paper mainly discusses the development history of air source heat pump technology at home and abroad, working principle, working flow, turbo technology at present stage, efficient heat exchange, and the research status of air source heat pump technology, such as new type refrigerant and dual frequency compression frequency conversion, then it discusses the application of air source heat pump technology, has the advantage, and finally discusses its application and the existence of two major problems and suggestions for improvement.
\end{abstract}

Key words: air source heat pump; water heater; energy saving and emission reduction; research status

\section{Introduction}

With the energy-saving environmental policy put forward, the advantages of air-source heat pump has been accepted by the majority of users. First of all, the air as a low-temperature heat source, inexhaustible, everywhere, can be used unconditionally. Second, a machine, winter hot water, summer cooling, you can save a set of cooling water systems and boilers. Third, can be installed in the outdoors, the effective area, do not take the building easy installation, easy operation and management. Finally, the equipment is well equipped with the protection and control system, the equipment is highly reliable. The working principle of the air source heat pump is the inverse Carnot cycle principle, which is a kind of energy application way of absorbing heat from the air and conveying it to the indoor heating. Energy saving and emission reduction has become the trend of the times today, saving energy and reducing carbon emissions is the most fashionable way of life, the air source of green, low-carbon emission reduction features bring the air source heat pump more broad market, especially with double level compression, cascade cycle, variable frequency compression, turbo, efficient heat transfer technology and the development and use of air source heat pump technology frost technology corresponding solution, its application prospects are more and more widely.

\section{Air source heat pump working principle and process}

2.1 Air source heat pump works

Air source heat pump is a new type of hot water production equipment. Air source heat pump water heater, also known as 'air source heat pump water heater', 'heat pump water heater' 'air to water heater' and so on.

The air source heat pump mainly consists of two parts: one is the air source and the other is the heat pump. Air source is the source of heat, heat pump is the use of relatively little energy (such as electricity) to heat from the low temperature environment to a high temperature environment of an energy-saving device, its working principle and the refrigerator is similar, according to Carnegie cycle work, the difference is only the working temperature range is not the same.

A complete air source water heater consists of two main parts:

Making the air-conditioning part and heating the hot water part. But in fact these two parts are closely linked together, inseparable, must work at the same time. That is, heating the hot water at the same time, to the kitchen cooling. Or when the kitchen is cooled while heating hot water.

Air source heat pump central hot water unit generally by the compressor, condenser, evaporator, throttle device, filter, tank, check valve, solenoid valve, condensing pressure regulating valve, storage tank and other parts. The system diagram shown in Figure 1

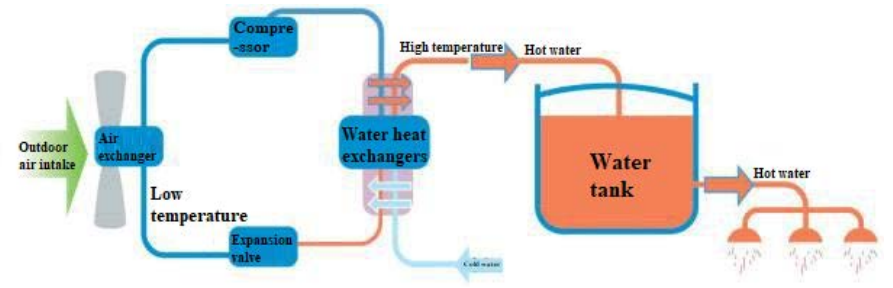

Figure 1 air source heat pump system diagram

Air source heat pump works:

2.1.1. Low-temperature low-pressure refrigerant by the expansion mechanism throttling pressure, into the air exchanger evaporative endothermic, from the air to absorb a lot of heat $\mathrm{Q}_{\mathrm{A}}$.

2.1.2. Evaporative heat-absorbing refrigerant enters the compressor in gaseous form and is compressed to become hightemperature and high-pressure refrigerant (the heat stored in the refrigerant is divided into two parts: one is the heat absorbed from the air $\mathrm{Q}_{\mathrm{A}}$, part of the input compressor energy in the compressed refrigerant into the heat $\mathrm{Q}_{\mathrm{B}}$ ).

2.1.3. The compressed high temperature and high pressure refrigerant enters the heat exchanger, releases its heat $\left(Q_{A}+Q_{B}\right)$ into the cold water into the heat exchanger, and the cold water is heated to $55^{\circ} \mathrm{C}$ (up to $65^{\circ} \mathrm{C}$ ) Insulation tank storage for users to use.

2.1.4. After the heat of the refrigerant into the liquid form into the expansion mechanism, throttle down, so endless circulation. The heat in the environment is transferred to the water by allowing the refrigerant to continue to evaporate (heat in the environment) $\rightarrow$ compression $\rightarrow$ condensation (heat release) $\rightarrow$ throttle $\rightarrow$ reevaporative heat cycle.

Air source water heater with air conditioning principle has some similarity, and the application of the inverse Carnot principle. By absorbing a large amount of low-temperature heat in the air, the heat that becomes compressed into a high temperature after being compressed by the compressor is transferred to the tank and the water 
is heated. The whole process is an energy transfer process (transferred to water from the air), not in the energy conversion process, none of which is through the electric heating element, hot water for heating, or combustion of the combustible gas produced by hot water In the heating. Therefore, the use of heat pump technology can save a lot of energy, air to water heater is the traditional electric water heater $1 / 4$, gas, fuel water heater $1 / 6$, coal-fired boiler $3 / 5$, solar water heater $1 / 2$.

\subsection{Air source heat pump work flow}

Air source heat pump work flow shown in Figure 2: Compressor will return the low-pressure refrigerant after compression, into a high temperature and high pressure gas discharge, high temperature and high pressure refrigerant gas flowing through the copper tube outside the tank, the heat conduction to the copper In the tank, the cooled refrigerant flows into the liquid under the continuous action of the pressure, and then enters the evaporator through the expansion valve. As the pressure of the evaporator suddenly decreases, the liquid refrigerant evaporates rapidly into a gaseous state and absorbs a lot of heat. At the same time, under the action of the fan, a lot of air flows through the outer surface of the evaporator, the energy of the air is absorbed by the evaporator, the air temperature is rapidly reduced, into the air into the kitchen. Then absorb a certain amount of energy back to the compressor refrigerant, into the next cycle.

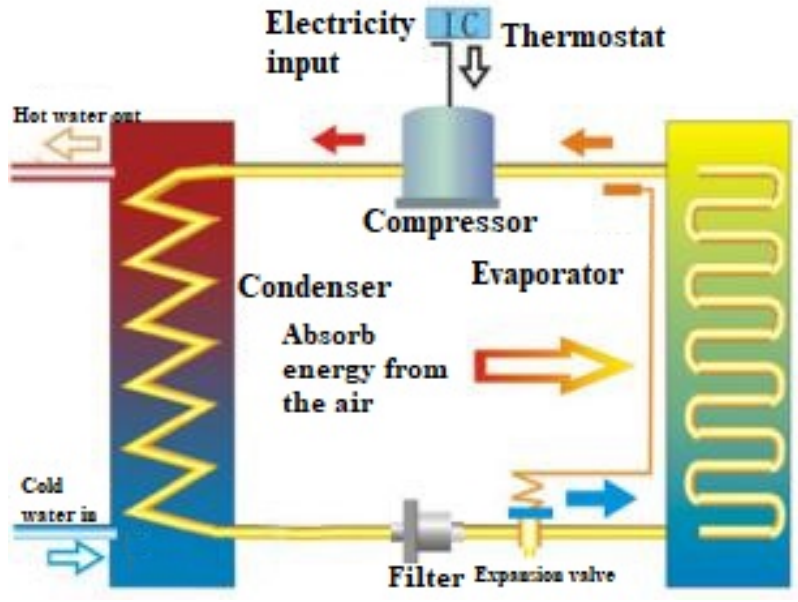

Figure 2 air source heat pump working flow chart

\section{Air source heat pump heating method}

\subsection{Direct heating}

Evaporator and condenser are in the host, the cold water directly into the host, the condenser by a one-time direct heating to the preset temperature, and then under the action of cold water pressure, directly to the insulation tank. The advantage is to keep the water is the default temperature that is, people need hot water, energy-saving effect is better; the disadvantage is that when the water temperature in the water tank, but also pumped back to the host to use the heating or auxiliary heating.

\subsection{Recycling}

The evaporator and the condenser are in the mainframe, but the cold water directly into the insulation tank, and then pumped back to the host heating, must be more than a circulating pump, heating is a hierarchical cycle heating, because it is the water temperature after several cycles of heating to the preset temperature. The advantage is that the energy efficiency is relatively straightforward, because the temperature to be increased is closer to the original temperature, the better the heat transfer effect and the higher the energy efficiency. The disadvantage is that the need to use a circulating pump will waste some electricity, hot water pipe diameter is longer, so the energy consumption to be more, cold water from the above into the insulation tank, from below the hot water, and the general hot water than a cold container of water is usually above the heat than the following, so the above cold water will lead to the water temperature cannot be constant, will be mixed with water.

3.3. Separate direct thermal type (also known as: fast thermal type)

Only the evaporator in the host, the condenser is in the insulation tank, cold water from the following injection, hot water is through the cold water upward top force discharge, so it does not have to like the recycling machine must be circulating pump, and its condenser directly in the tank and heat exchange heat, so heat transfer directly, do not go through any diameter, so that energy efficiency and heating rate must be higher than the cycle machine, because it from the top of the hot water, so can basically keep the hot water discharged. If the special circumstances must be recycled, then the way the size of the tank can be resolved, so his other advantage is to have a strong variability.

\section{Air source heat pump the main technology and its advantages}

\subsection{Air source heat pump main technology}

\subsubsection{Turbo technology}

The use of turbo technology air source heat pump, start the compressor at the same time, start the turbo function, so that the compressor output power instantaneous increase of about $20 \%$, thus achieving a rapid rise and fall, and the air source heat pump quickly reach the preset temperature and into the insulation phase, a serious start-up phase of the time is greatly reduced, so as to achieve the purpose of energy conservation. Compared with the general compression technology, its shortened start time can reach about $40 \%$, thus saving about $30 \%$ of electricity. Turbo technology using the start time of the heat pump and the general heat pump start time comparison shown in Figure 3.

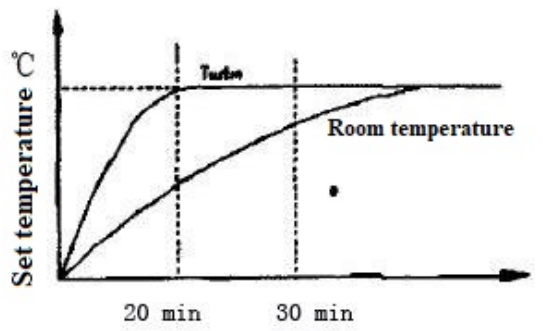

Figure 3 Comparison of heat pump and general heat pump using Turbo technology

\subsubsection{Efficient heat transfer technology}

Energy efficient air conditioning is achieved by increasing the heat transfer surface with air. According to the natural physical phenomenon 'water evaporation efficiency' principle, relying on evaporation to absorb the heat in the air to achieve the purpose of cooling: When the hot air through the actual heat transfer area of 100 times the water evaporation of the wet curtain, the large amount of heat are absorbed by the air so as to achieve the process of air cooling. So it's compared with the traditional compression technology, its characteristics are not reflected in the compressor, but reflected in the increase in the heat transfer surface.

\subsubsection{The use of new refrigerant}

Developed a new type of refrigerant, so that the air source heat pump system with the ambient temperature changes, and change the 
refrigerant to participate in the cycle. This type of system is complex, how to use this technology is based on the actual situation to determine the composition of the refrigerant, filling, how to solve the refrigerant leakage rate on the system thermal performance. With R505A and R404A working fluid, it can operate stably at high compression ratios, but COP is relatively low relative to other cryogenic heat pump systems. Has been proposed non-azeotropic refrigerant, by changing the system of mixed refrigerant composition and other methods to improve and improve the air source heat pump in the low temperature environment of the heating performance.

4.1.4. Two-stage compression frequency conversion technology ${ }^{[2]}$ Aiming at the characteristics of low heating performance and high exhaust gas temperature in the single-stage system, a two-stage compression frequency conversion air source heat pump system is proposed. When the evaporation temperature is less than -25 degrees and the compression ratio of the compressor is more than 8 , two-stage compression technology. The low pressure steam from the evaporator is first sucked through the low pressure (first stage) compressor of the compressor to the gaseous refrigerant compressed to the intermediate pressure. The vapor cooled by the intercooler is then inhaled by the high pressure stage (secondary), compressed to the condensing pressure and discharged into the condenser. The working flow is: low pressure cylinder suction - low pressure level compression - low pressure cylinder exhaust - medium pressure cooling (intercooler) high pressure cylinder suction - high pressure level compression - high pressure cylinder exhaust (condensing pressure), using a throttling not completely cooled, two-stage compression. Variable frequency compression technology is relative to the constant speed of the compression technology, it is a way through the control or means to speed within a certain range of continuous adjustment, and can continuously change the output energy compression technology. The core component is the frequency converter. The frequency converter adjusts the compressor's speed by changing the supply frequency of the compressor. Rely on the speed of the compressor speed to achieve the purpose of controlling room temperature. Room temperature fluctuations, less power consumption, comfort to a large extent have improved. The use of frequency control technology inverter air conditioner, according to the ambient temperature automatically select the heating, cooling and dehumidification operation, so that the room can not only quickly meet the needs of the temperature in a short time, and can in low speed, low energy consumption to small temperature fluctuations, to achieve a fast, energy saving and comfortable control of the temperature effect. The two combine to form a two-stage compression frequency conversion air source heat pump. Figure 4 shows the two-stage compression frequency conversion air source heat pump system schematic diagram,

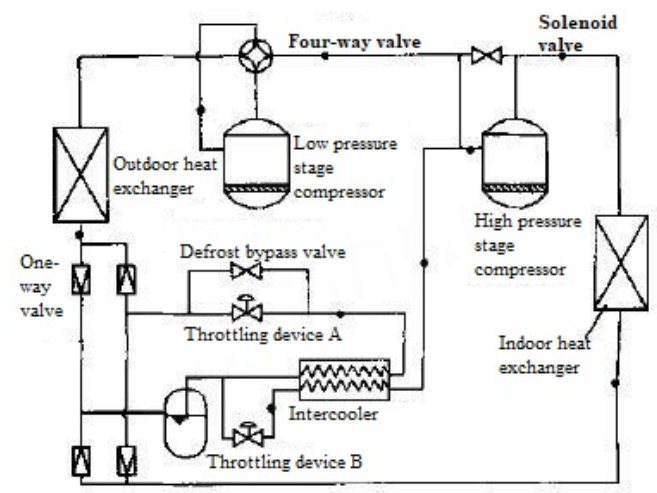

Figure 4 Schematic diagram of two-stage compression frequency conversion air source heat pump system
The system changes the flow of refrigerant by switching the fourway valve and the solenoid valve to achieve refrigeration, single-stage compression and two-stage compression heating. Refrigeration conditions and single-stage compression heating conditions and general air source heat pump system, high pressure level of the studio does not work, throttle device B closed, solenoid valve open. Refrigeration conditions, the four-way valve power and cooling position, the indoor heat exchanger for the evaporator, and outdoor heat exchanger for the condenser; single-stage compression heating conditions, the four-way valve at this time in the heating position, indoor heat exchanger for the condenser, outdoor heat exchanger for the evaporator. When the ambient temperature is low, open the throttle device $\mathrm{B}$, close the solenoid valve, high pressure class compressor put into operation, heat pump system began to work in accordance with two-stage compression heating conditions. In the winter heating condition, the defrosting of the outdoor heat exchanger is carried out by the reverse defrosting method. The defrosting bypass valve is opened when defrosting, and the frequency of the low pressure class compressor is increased, so that the defrosting time can be shortened.

In addition to the two-stage compression technology, there are two-stage coupling technology and cascade heat pump technology, to solve the air source heat pump low temperature applicability problem can also play a significant effect. Two-stage coupled heat pump system, the use of air source heat pump from the outdoor air to absorb heat, the preparation of $10 \sim 20{ }^{\circ} \mathrm{C}$ water as a low heat source of water source heat pump, and then make a higher temperature hot water heating to the building, the heat pump unit low temperature the scope of operation will be effectively expanded. For a cascade heat pump unit, the unit can be switched between a single stage and a cascade cycle via a solenoid valve. The calculation results show that the unit can also be energy efficient during the lower outdoor ambient temperature in winter.

\subsection{Air source heat pump research}

4.2.1 Air source heat pump frost and defrost problem study [3]

How to deal with the air source heat pump frost, improve the efficiency of the air source heat pump, has done a lot of technical research, including frost, prevent or delay research and defrost research.

1) Air Source Heat Pump Frosting Theory Study

Frosting is the basis for defrosting and preventing or delaying frosting, and it is also quite complicated. Through the introduction of the theory of the model to carry out research. According to the nucleation theory, crystal dynamics theory and meteorological theory, a more accurate mathematical model of frost formation is established and the research on frost suppression is carried out. The influence of frost on the heat transfer characteristics and heat pump performance of the evaporator was studied from two aspects of theory and experiment. In order to analyze the effect of frost on the performance of the evaporator, the mathematic model of the air - air heat pump evaporator was established based on the distribution parameter method on the basis of the heat and mass balance and the pressure balance. The frost model and the heat transfer characteristics are linked to establish a detailed mathematical model of finned tube heat exchanger frosting model and finned tube evaporator under frost condition.

2) Air source heat pump frosting experimental study

The frosting process of the finned tube heat exchanger is mainly studied by experiment, because the geometrical shape of the heat exchanger and its surface shape are more complicated. Therefore, only through the experimental study of different fin structure with the heat exchanger frost state performance changes, and the use of frost after the dynamic process of taking pictures by means of computer image 
processing methods and complex geometric surface of the frost and its quantitative analysis of the distribution of frost thickness along the air flow direction can provide quantitative experimental data for the simulation of the dynamic frosting process of the finned tube evaporator. The experimental results show that with the increase of the air flow rate, the duration of the super-cooled water droplets is shortened and then the frozen particle size increases, but the effect of the air flow rate on the initial frost crystal shape is not obvious. Through a large number of experimental studies, has been on the frost of the physical process and frosting law, and for the next step to prevent or delay frost and defrost research laid a good foundation.

3) Air source heat pump to prevent or delay the frost method research

(1) Change the ambient parameters of the outdoor heat exchanger

On the outdoor heat exchanger around the air state and its surface frost is closely related to the problem, done a lot of research. In the outdoor heat exchanger inlet layout of solid dehumidifier, to reduce the outdoor heat exchanger inlet air moisture content, thereby inhibiting frost. The results show that the solid dehumidifier has a certain effect on the inhibition of frosting with the length of time. At the beginning of the period, the solid dehumidifier has obvious effect on the inhibition of frosting, but with the decrease of the ability of the dehumidifier to absorb the water vapor, the role of frost also will be reduced. The installation of an adsorbent bed at the inlet of the evaporator to reduce the inlet air humidity is used to suppress the frosting of the evaporator surface. As the system can only run intermittently, in the absence of sun exposure time, the adsorption bed regeneration mainly rely on the adsorption bed of the electric heater to complete. There is also a heat pump system to assist the outdoor heat exchanger. During the normal operation of the heating operation, the auxiliary outdoor heat exchanger can improve the air temperature around the main outdoor heat exchanger and thus delay the frosting effect.

(2) To change the unit system flow or evaporator structure parameters

There is not much research on changing the air source heat pump system process. By connecting a bypass pipe between the compressor outlet and the evaporator inlet, the surface of the evaporator is prevented from frosting by increasing the flow rate of the refrigerant in the bypass pipe, but the heating rate of the evaporator is increased reduce. Through the heat pump system in the indoor heat exchanger, plus a refrigerant electric heater. When the electric heater is connected, the working fluid pressure and temperature of the system are higher than that of the ordinary system, so that the surface temperature of the outdoor heat exchanger is $1 \sim 2{ }^{\circ} \mathrm{C}$ higher than that of the ordinary heat pump system, which can effectively delay the frosting time. But the system consumes electricity and the process is complex. The results show that when the area of outdoor evaporator is doubled compared with the original one, the evaporation temperature of the heat pump unit is increased by about $2.5^{\circ} \mathrm{C}$, and the frosting time of the unit is reduced by $5.1 \% \sim 82 \%$. In addition, the study also shows that by increasing the airflow along the direction of the flow direction of the rib size, but also reduce the tendency to frost; increase the fin spacing can delay the frost, but the interdiffal humidity on the inhibition will produce influences.

(3) Change the evaporator surface characteristics

Through the surface treatment technology in the outdoor heat exchanger surface to add hydrophobic coating can make water droplets, so easy to fall off, thus delaying the frost. It has also been shown that the frost layer on the hydrophilic surface is thinner than the frost on the surface, and the surface frost density is larger and the ability of the hydrophilic coating to delay the frost will decrease with the increase of the relative humidity. The effect of delaying frosting was significantly stronger than that of hydrophilic treatment. Although a lot of research work has been done to delay frosting, some of the technology can delay the formation of frost, but due to the application conditions, efficiency, technical and economic constraints, to prevent or delay the study of frost has not yet take the obvious breakthrough progress, there is no way to find a practical way.

4.2.2 Air source heat pump defrost characteristics and control methods of the study [4]

Air source heat pump defrost method is divided into: artificial or mechanical removal of outdoor heat exchanger on the frost; electric heater or steam heater defrost; shower defrost; hot air defrost. At present the hot air defrost method has become the main defrost method.

Study on defrosting characteristics of air source heat pump

The defrosting process is a very complex process, but through a large number of studies has achieved remarkable results. The research mainly includes the research of defrosting mathematical model, the experimental study and the influencing factors of defrosting.

(1) In theoretical research

In 1974, Sanders established the mathematical model of evaporator defrost. The evaporative water solution equation is now a commonly used equation to study the defrosting problem. O'Neal D.L confirms the usability of the model by experimental analysis. In 1992, Krakow K.L., based on the electric heating defrosting experiment, proposed the frost layer melting process of mathematical physics model of the closest. At present, the mathematical model of frost layer melting was established on the basis of the simplification of the defrosting process. And proposed a four-way valve for the system after the high and low pressure balance to re-establish a mathematical model, and carried out on-site experimental study, the results and experimental results are very similar. For the surface temperature distribution of the finned tube of the outdoor heat exchanger measured by the defrosting experiment, a dynamic model of water evaporation on the surface of the outdoor heat exchanger was established. Through the analysis of the proportion of the energy in each part of the defrosting process, defrosting energy comes mainly from the compressor work and heat from the heating environment to absorb the heat, the two about each account for about $40 \%$.

(2) Study on influencing factors of defrosting

In all components, throttle devices, high pressure reservoirs and gas-liquid separator on the defrosting effect of the most obvious. Through the use of electronic expansion valve and thermal expansion valve defrost process research, that the use of electronic expansion valve can effectively reduce the defrost time. Experiments show that removing the gas-liquid separator from the system can reduce the defrost time by $10 \%$, while the overall system integrated COP only reduced by about $2 \%$. It has also been proposed to add a resistance wire to the refrigerant in the gas-liquid separator. The experimental results show that the system integrated COP is increased by about $3.1 \%$ and the defrost cycle time is shortened by about $11 \%$. The main reason for the poor defrosting effect of the heat pump unit is that the system refrigerant quantity is insufficient, and it is pointed out that the use of the refrigerant compensator instead of the high pressure reservoir can shorten the defrosting time and prove the effect by experiment. As well as the opening of the fan on the impact of defrost, open the fan in advance to reduce the indoor and outdoor coil refrigerant pressure, thereby reducing the system to restore the heating operation of the compressor and refrigerant pipe mechanical shock, that $20 \mathrm{~S}$ open fan ideal. Through the early opening of the fan on the impact of defrosting study shows that: early to open the fan can effectively avoid defrost due to excessive exhaust pressure caused by the system downtime. 
Study on defrosting control strategy of air source heat pump

The current defrosting method on the basis of defrosting methods are mainly the following:

(1) Timing control method

(2) Time-temperature method

(3) Current control method

(4) Air pressure defrost control method

(5) Indoor and outdoor dual sensor defrost method

(6) Frost layer sensor method

(7) The best defrost time control method

(8) The maximum average heat supply method

(9) Maximum cycle heating coefficient method

Now apply the fuzzy control to defrost, and put forward the fuzzy intelligent control defrost method. Although defrost control methods are diverse, but not perfect, not yet mature, still have to continue to study. The actual operation is still difficult to do on-demand defrosting, defrosting process stability and reliability cannot be effectively resolved. The main problem is that some of the parameters used to determine the end of frost or defrost, such as time, temperature and pressure, because it is difficult to accurately reflect the heat pump frost and defrost the actual working conditions, some theoretical control parameters, such as the maximum average heat supply, maximum cycle heating coefficient, the best defrost time, in practice it is difficult to measure accurately.

\section{Air Source Heat Pump Application and Existing Problems}

\subsection{Application of air source heat pump}

Air source heat pump technology is currently mainly used in water heaters and air conditioning. From the functional aspects of use, it can be used for refrigeration, floor heating, central hot water. Air source heat pump air conditioning is suitable for more than 150 square meters of high-end apartments, a system can be achieved central air conditioning, floor heating, central hot water three functions, compared to conventional central air conditioning, energy saving $20 \%$ to $30 \%$. The current air source heat pump is mainly the use of single or multi-level parallel way. Its application is very extensive, and with our lives are closely related. Such as our side of the enterprises and institutions: schools, factories and hospitals; leisure and entertainment: hotels and sauna center. The following describes their application.

\subsubsection{Student apartment}

Use multiple parallel, automatic control, host and water tank dormitory configuration, advanced automatic POS cash register or regular water supply system. According to the different seasons, the students of the different water consumption seasonal adjustment. In the summer, hot water demand is small, less heating, in winter, hot water demand, more heating. A long hot water, hot water, to avoid solar water heaters in the summer during the summer to create a lot of hot water, but students do not use hot water holiday, every day must be water to reduce the temperature, wasting a lot of water trouble.

\subsubsection{Factory hospital}

Using single or multi-machine parallel, according to the staff to get off work system using sub-time water supply, flexible, more energy conservation, to overcome the use of solar water heaters by rain, no hot water in winter, water temperature instability and other shortcomings.

\subsubsection{Hotels}

Using single or multi-level parallel, fully automatic control and improve the water supply and return system, the use of Germany wilo booster pump and circulating pump to ensure that the hotel water supply system stability. Can provide room water and sauna pool bath, zero pollution, for the hotel to save energy at the same time create a green environment, but also according to the peak and valley to change the strategy, the use of electricity, more economical.

\subsubsection{Sauna pool}

Use of multi-machine parallel, the use of titanium, plate, fixed pipe for water heater, corrosion-resistant, safe and durable, more energy efficient, automatic heating, constant temperature, providing hot water and cold water to solve large-scale heated swimming pool and sauna high, the complexity of the operation cycle process, both to save high costs and get security guarantee.

\subsubsection{Beauty salons}

Using a host to heat the two tanks, the area is small, fast heating, the use of heating at the same time the way to solve the high water consumption of electric water heaters, and gas water heater unsafe defects.

\subsubsection{Villa family}

The host plug in the wall, the water tank placed in the balcony, while saving energy and play a safe and beautiful, and the seamless structure of the building, compared with the solar water heater, with a simple installation, does not affect the overall beauty of the building advantages.

\subsection{Air source heat pump problems}

According to the IEA (International Energy Agency) survey [5], the current air source heat pump accounts for about $27 \%$ of the global heat pump. In China, home air conditioning, about $70 \%$ of the air source heat pump air conditioning. Air-source heat pump 'renewable energy + high energy-heating-waste-renewable energy' part of the energy cycle feedback cycle of the heating process (cold) mode is an advanced energy model, its energy saving and environmental protection features air source heat pump in the application of HVAC will be more extensive. However, the practice shows that the operation of the air source heat pump at this stage is not very satisfactory, there are still some problems to be solved. Mainly for the two aspects [6]:

5.2.1 Air source heat pump frost and defrosting problem;

5.2.2 Air source heat pump low temperature adaptability.

Due to the above two reasons, the impact of air source heat pump is severely restricted. Destined the heat pump market will be mainly south of the Yangtze River and its vicinity.

\section{Air source heat pump to improve the direction of recommendations}

Although the application of air source heat pump technology still has some problems, but with the turbo technology, two-stage compression technology, frequency conversion technology, the current air source heat pump technology greatly improved and improved. Moreover, the heat pump technology is an energy technology in the twenty-first century, the energy through the heat pump in the form of transmission, can improve the use of energy efficiency, energy efficiency has two meanings, from the environmental point of view, can reduce greenhouse harmful gases and greenhouse gas emissions, reduce the harmful factors of the environment, from another point of view, is to solve the power of a high-altitude load of a technology, in a sense to reduce the burning of fossil fuels, played a mitigation of the arrival of the energy crisis effect. Especially in today's shortage of resources, energy saving and environmental protection has become the main era, air source heat pump technology is bound to have a broad application prospects.

However, air-source heat pump technology frost defrosting problems and low temperature adaptability problems, cannot be ignored, these two issues is to determine the efficiency of air-source heat pump to improve and expand the scope of application of the key factors, and frost defrost problems and low temperature adaptability 
problems still exist, yet to be resolved, therefore, to improve the air source heat pump technology is still engraved.

From a large number of experimental studies and references, air source heat pump technology in the air source heat pump reverse cycle defrosting energy distribution and the use of compressor heat storage to reduce the energy consumption of defrost should be further studied for air source heat pump system processes and evaporator surface characteristics of the study is not enough, should also be further.

\section{REFERENCES}

[1] He Yilong. Analysis of air source heat pump technology development and application [J]. Value Engineering, 2010, 29 (19): 93.

[2] Tian Changqing, Shao Shuangquan, Shi Wenxing, et al. Frequency conversion air source heat pump technology [J]. Fluid Mechanics, 2005, 33 (9): 69-70.

[3] CAO Xiao-lin, CAO Shuang-jun, DUAN Fei, et al.Progress and prospect of deflagration of air source heat pump [J]. Fluid Mechanics, 2011, 39 (4): 75.

[4] Fu Shaofeng. Air source heat pump frost and defrost the research status [J]. Zhejiang Architecture, 2010, 27 (10): 61-63.

[5] Chen Zhenkai, Hu Wenju, Jiang Huimin, et al. Restricted air source heat pump to promote the application of technical factors of the status quo [J]. Refrigeration and air conditioning, 2012, 12 (1): 12-15.

[6] Chaiqinhu, Ma Guoyuan. Status and progress of low temperature adaptability of air source heat pump [J]. Energy Engineering, 2002 (5): 2-9.

[7] Wang Fang, Fan Xiaowei. China air source heat pump technology progress [J]. Energy Engineering, 2002 (4): 2-3.

[8] Rao Rongshui, Gu Bo, Zhou Ze, et al. Progress of air source heat pump in cold area [J]. Building Thermal Ventilation and Air Conditioning, 2005, 24 (4): $25-26$

[9] Zhang Bin, Zhang Zhirong, Yang Bin. Air source heat pump system debugging problems and countermeasures [J]. Technical exchanges, 2010, 31
(5): 67-68.

[10] Yao Yang. Simulation and analysis of winter defrosting conditions of air source heat pump hot and cold water unit [J]. Harbin: Harbin Institute of Technology, 2002.

[11] Wang Yang, Jiang Huimin, Ma the best. Increase the evaporator area to delay the air source heat pump hot and cold water unit frost test and points [J]. HVAC, 2006, 36 (7): 83-87.

[12] Tian Changqing, Shi Wenxing, Wang Sen. Study on two - stage compressed frequency air source heat pump in cold region [J]. Journal of Solar Energy, 2004, 25 (3): 388-393.

[13] Zhang Jutai. Air source heat pump hot and cold water unit in the Jiaodong area operation effect design attempt and technical and economic analysis [J]. HVAC, 1997, 27 (6): 17-20.

[14] Zheng Gang, Gu Bo, Wang Zhiyi. Air-source heat pump fan performance on the impact of frost [J]. HVAC, 2004 (9): 51-53.

[15] Jiang Y, et al. Calculation of frost loss coefficient of air source heat pump frost. Heating and Air Conditioning, 2000, 30 (5): 24-26 (in Chinese with English abstract).

[16] Wang Zhiyi, Wang Xinmin, Dong Zhiming. Defrost improvement by heat pump refrigerant charge eompensating [J]. Applied Energy, 2008, 85 (11): 1050-1059.

[17] Ameen F.R. Study of frosting of heat pump evaporators [J] .ASHRAE Trans, 1991, 99 (1): 61-71.

[18] Eckman R.L. Heat Pump Defrost Controls: a Review of Past, Present, and Future Technology [J]. ASHRAE Trans, 1987, 93 (1): 1152-1156.

[19] Sami S M, Tulej P J. A new design for an air source heat pump using a ternary mixture for cold climate [J]. Heat Recovery Systems lu0026 Chp, 2001, 15 (6): 521-529.

[20] Shuangquan Shao, Wenxing Shi, Xianting Li, Ma Jie. Ablew Inverter Heat Pump Operated All-year-round With Domestic Hot Water [J]. Energy conversion and management 2004,45 (13-14): 2255. 